$$
\text { "tothpeter" — 2005/2/17 — 18:12 — page 385 — \#1 }
$$

\title{
Taking learning styles into consideration in e-learning based education
}

\author{
PÉTER TÓTH
}

Abstract. In improving electronic teaching material processes we should take the student's learning styles or methods into consideration. The ways learners receive information may be shared into three categories (modalities): visual, auditory, kinesthetic (tactile). In this paper I present some pedagogical questions of the electronic teachinglearning environment, offer a brief survey of the different learning style theories and emphasise the importance of the modalities in encoding information. The electronic teaching material should encourage the learner to choose an appropriate form of syllabus by which his knowledge can become more efficient.

Key words and phrases: teaching and learning styles, electronic teaching material, elearning, problem solving, Modality Preference Inventory.

ZDM Subject Classification: B20.

1. The pedagogical aspects of the electronic teaching-learning process

Electronic education, like education in general, takes place in order to achieve certain pre-defined objectives, the achievement of which results in the formation and development of students' knowledge that is of an adequate level and is achievement competent. The educational objectives form a hierarchy, the description of which was carried out in the 50ies and 60ies by Bloom, B. S. [1956] and his colleagues (Krathwohl, D. R. et al., 1964) in the three fields of personality development: cognitive, affective and psychomotoric (taxonomy investigations). In 
order to acquire achievement competent knowledge, electronic learning may be realised at four levels of environment:

- through the acquisition of knowledge (facts, concepts, relations, regularities, procedures, etc.) that is dynamic and integrated into a system - type 1

- the application and practice of knowledge (acquisition of expertise and abilities) through students' interaction - type 2

- processing the syllabus requires the co-operation of students (student-teacher communication system - virtual classroom) - type 3

- processing the syllabus through group work, the combination of traditional classroom and electronic education - type 4

Comparing the above mentioned four types of learning environment with Bloom's cognitive object and achievement levels, the following electronic education system is to be specified (Figure 1):

\begin{tabular}{|c|c|c|c|c|}
\hline & type 1 & type 2 & type 3 & type 4 \\
\hline Knowledge & $\begin{array}{l}\text { Web pages; } \\
\text { Web presenta- }\end{array}$ & \multirow{4}{*}{$\begin{array}{c}\text { Computer } \\
\text { Based } \\
\text { Training } \\
\text { (CBT) }\end{array}$} & & \multirow{6}{*}{$\begin{array}{c}\text { Training as a } \\
\text { combination of } \\
\text { traditional and } \\
\text { e-learning }\end{array}$} \\
\hline Understanding & $\begin{array}{c}\text { Electronic } \\
\text { course books }\end{array}$ & & & \\
\hline Application & & & \multirow{3}{*}{$\begin{array}{l}\text { Virtual class- } \\
\text { room; } \\
\text { Electronic } \\
\text { communica- } \\
\text { tion system - } \\
\text { on-line }\end{array}$} & \\
\hline Analysis & & & & \\
\hline Synthesis & & & & \\
\hline Evaluation & & & & \\
\hline
\end{tabular}

Figure 1. The types of electronic educational systems

With respect to the operation of electronic educational system shells, three educational forms of e-learning are to be distinguished: (Pentelenyi, P. - Toth, P., 2002) 
"tothpeter" — 2005/2/17 — 18:12 — page 387 — \#3

- training of individual timing (CBT)

The syllabus is stored on a LAN base server or on CD. Students are to decide themselves when and how much time they want to allot to syllabus processing. The syllabus is divided into smaller units which can be processed in 2025 minutes, therefore students' attention is ensured. The students' work is directed jointly by the structure of the syllabus and navigation opportunities, so they need to be easily manageable and logically structured. The easy processing of the syllabus is ensured by a varied set of media (animation, video, and simulation exercises beside the media contained in electronic course books). Before the application of each syllabus module, the students' level of knowledge is tested to decide whether processing the particular syllabus is necessary or not. End of module testing is to show the success of knowledge acquisition. Testing is electronic.

- synchronous training (virtual classrooms)

Here, too, syllabus is stored on a central server, however, its processing is fully directed and supervised by a teacher during the training. Students can follow the syllabus through their own computer. Part of the system may be an electronic board as well, on which the teacher may write or draw, and which appears on the students' computer. Experiments and simulation exercises presented by the teacher appear at the students' place of work. The knowledge imparting system is completed by very sophisticated communication: live audio and video contact between the teacher and the participants at the training; e-mail contact, chat between the teacher and the students or among students. Testing may take place orally or in an electronic form, and it may be targeted at the entire group of teachers or a single student alike. The methods applied in the system are very similar to those in traditional education.

- asynchronous training

It is in fact none other than a variant of training of individual timing completed by electronic communication. Students may keep in touch with one another or the teacher through e-mail and/or electronic debates.

On examining the electronic educational process, the following seven phases may be distinguished:

- motivating students and the continuous sustaining of interest and attention are essential elements of electronic education 
- introduction of knowledge (facts, concepts, relations, regularities, procedures, etc.) enriched by a varied set of media

- generalisation and abstraction of knowledge acquired so far, exposure of the inner logical relations of the syllabus, execution of higher thought operations (analysis, synthesis, comparison, relations, etc.)

- the classification of knowledge promotes its retaining (remembrance) and its application in various work and problem situations

- presentation of the application of acquired knowledge through sample problems

- making students practice

- testing and evaluation of students' achievement

Taking all this into consideration, Merill, M. D. [1994] accomplished the analysis of electronic syllabuses and found that the following relations, as seen in the table in Figure 2, may be set between syllabus contents and students' achievement (fixed in curricula).

\begin{tabular}{|c|l|l|l|c|}
\hline students' achievement & \multicolumn{4}{|c|}{ most important types of syllabus contents } \\
\cline { 2 - 5 } & facts & concepts & procedures & rules \\
\hline remembrance & & & & \\
\hline application & & & & \\
\hline conclusion & & & & \\
\hline
\end{tabular}

Figure 2. The matrix of electronic syllabus content and students' achievement

Based on the above matrix, two main forms of information transfer are to be distinguished:

- primary forms of information transfer

- rule explanations

- examples

- test questions

- exercises

- secondary forms of information transfer

- drafting preconditions of training

- defining objectives

- providing support

- feedback 
"tothpeter" — 2005/2/17 — 18:12 — page 389 — \#5

\section{The role of learning style in electronic education}

In the developing process of electronic syllabuses the learning style of participants at the training has to be taken into consideration, too, because given this knowledge the independent learning problems of students can be overcome. Kolb, D. A. [1984] regarded the learning process circular (Figure 3).

Students try to justify their ideas in practice as well. Their experience gained this way affects their original ideas by reinforcing or, on the contrary, refuting them (gaining experience $\rightarrow$ generalisation $\rightarrow$ gaining experience $\rightarrow$ generalisation $\rightarrow \ldots$. . According to Kolb, from this also follows the fact that the direction of learning is defined by the needs and objectives of the individual (motivation has become independent). It is especially true of electronic education. Therefore it can be stated that we cannot speak of efficient learning without clearly defining the objectives.

Kolb made a self-test (Learning Style Inventory), which can reveal the weak and strong points of learning. He thinks that four factors have a decisive role to play in learning - on the basis of Figure 3: (Kolb, D. A., 1984)

- concrete gaining of experience

These students generally find theoretical approaches to be unhelpful and prefer to treat each situation as a unique case. They learn best from specific examples in which they can be involved. These learners tend to relate to peers, not authority. Theoretical readings are not always helpful while group work and peer feedback often leads to success. Planned activities should apply learned skills. The instructor acts as helper for this self-directed autonomous learner.

- reflecting observation

These students rely heavily on careful observation in making judgements. They prefer learning situations such as lectures that allow the role of impartial objective observers. These students tend to be introverts. They prefer the information in visual and auditory forms. These learners want the instructor to provide expert interpretation. They look for an instructor who is both a "taskmaster" and a guide. They would like their performance to be measured by external criteria.

- creation of abstract concepts

These students tend to be more oriented towards things and symbols, and less towards other people, so they learn best in authority-directed, impersonal learning situations that emphasise theory and systematic analysis. They 
are frustrated by and gain little from unstructured "discovery learning" approaches such as exercises and simulations. Theoretical readings and reflective thinking exercises help these learners.

- active experimentation

These students learn the best when they can engage in such things as projects, homework or group discussions. They dislike passive learning situations such as lectures. These students tend to be extroverts and want to touch everything. Problem solving, small group discussions, peer feedback and self directed work assignments all help these learners. These learners like to see everything and determine their own criteria for relevance of materials.

(1) Converger/Pragmatist
(1) Diverger/Reflector

Comparing with reality

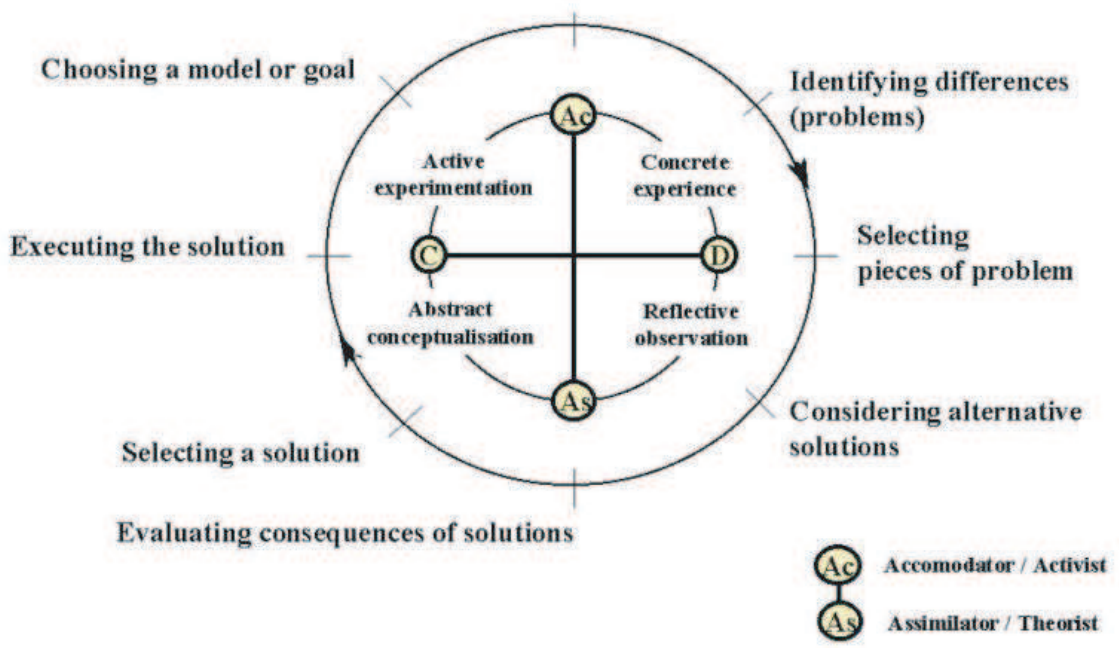

Figure 3. The main types of learning style according to Kolb, D. A. [1984]

The paired dominance of these results in four kinds of learning style:

- adaptable learning style

Its forte is active experimentation and concrete gaining of experience.

- assimilating learning style

Its forte is the creation of abstract concepts and reflecting observation. 
- convergent learning style

Its forte is the creation of abstract concepts and active experimentation.

- divergent learning style

Its forte is concrete gaining of experience and reflecting observation.

Understanding our students' learning style can make them an effective problem solver. Nearly every problem involves the following skills (Figure 3.):

- identifying pieces of problem,

- selecting pieces of problem to solve,

- seeing different solutions,

- evaluating possible results,

- implementing a solution. (Kolb, D. A., 1984)

Different pieces of the problem must be approached in different ways. If someone relies heavily on concrete experience, he or she may find that he or she can easily identifies problems that need to be worked on or solved. However, he or she may need to increase him or her abilities to evaluate possible solutions, as in abstract conceptualisation. If he or she may find that his or her strong points rest with carrying out or implementing solutions, as in active experimentation. If this is so, he or she may need to work on carefully selecting the problem, as in reflective observation.

Our students' abilities in learning and problem solving can be developed in following three ways:

- develop learning and work relationships with people whose learning strengths and weaknesses are opposite to theirs,

- improve the fit between their learning-style strengths and the kinds of learning and problem-solving experiences them face,

- become a flexible learner so practice and develop learning skills in their areas of weaknesses. (Kolb, D. A., 1984; Smith, D. - Kolb, D. A., 1985)

The ideal training environment such as e-learning as well would include each of the four processes. E.g. the electronic teaching material based learning cycle might begin with the learner's personal involvement through concrete experiences and then he or she reflects on this experience, looking for meaning, later the learner applies this meaning to form a logical conclusion and finally, he or she experiments with similar problems, which result in new concrete experiences. This cycle might begin anew due to new and different experiences. The e-learning 
"tothpeter" — 2005/2/17 — 18:12 — page 392 — \#8

activities should be flexible so that each learner could find suitable and efficient method to his or her learning style.

If we should demonstrate the differences between four learning styles we can describe it by learning a software program. The activist - who likes to learn using concrete experience and active experimentation - jumps in and does it straightaway. The theorist - who likes to learn using abstract conceptualisation and reflective observation - reads the manual to get a clearer grasp on what was performed. He likes to ask such question as "How does this relate to that?" The reflector - who likes to learn using reflective observation and concrete experience - thinks about what he or she just performed. The pragmatist - who likes to learn using abstract conceptualisation and active experimentation - uses the help feature to get some expert tips. (Conner, M. - Hodgings, W., 2000)

\section{The influence of the perception types on learning styles}

One theory of learning strategies focuses on the role of perception in e-learning based teaching-learning process. It is a well-known fact that the different media types play a determinative role in improving and applying electronic teaching materials, so we have to deal with the influences of perception types on learning styles.

Learning in a structured educational setting may be thought of as a two-step process involving the reception and processing of information. In the first step, external information (observable through the senses) and internal information (arising introspectively) become available to learners, who select the material they will process and ignore the rest. The second step may involve simple memorisation or inductive or deductive reasoning, reflection or action, and introspection or interaction with others. The outcome is that the material is either "learned" in one sense or another or not learned.

Felder, R. M. and Silverman, L. K. [1988] define a complex model in which they examine the connection of learning styles and teaching styles. They establish a student who favours intuitive behavioural routines over sensory perception, e.g., would respond well to an instructor who emphasises concepts (abstract content) rather than facts (concrete content). On the other hand a student who likes visual perception would be most comfortable with an instructor who applies images, pictures, charts, etc. Their model is based on the complex theories of Jung, C. G. [1933] and Kolb, D. A. [1984] (Figure 4). 


\begin{tabular}{|c|c|}
\hline Learning styles (methods) & Teaching styles (methods) \\
\hline sensory $\longleftarrow$ perception $\longrightarrow$ intuitive & concrete $\longleftrightarrow$ content $\longrightarrow$ abstract \\
\hline visual $\stackrel{\text { input }}{\longleftrightarrow \text { auditory }}$ & organisation \\
\hline inductive $\stackrel{\text { organisation }}{\longleftrightarrow}$ deductive & inductive $\stackrel{\text { organisation }}{\longleftrightarrow}$ deductive \\
\hline processing $\longrightarrow$ reflective & active $\stackrel{\text { student participation }}{\longleftrightarrow \text { passive }}$ \\
\hline 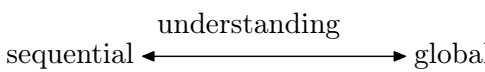 & sequential $\longleftarrow$ perspective \\
\hline
\end{tabular}

Figure 4. Dimensions of learning and teaching styles

According to these theories it should be important to harmonise applied teaching methods with students' learning styles. It is especially true in the case of electronic teaching material based learning environment, when there is no direct connection between students and teacher.

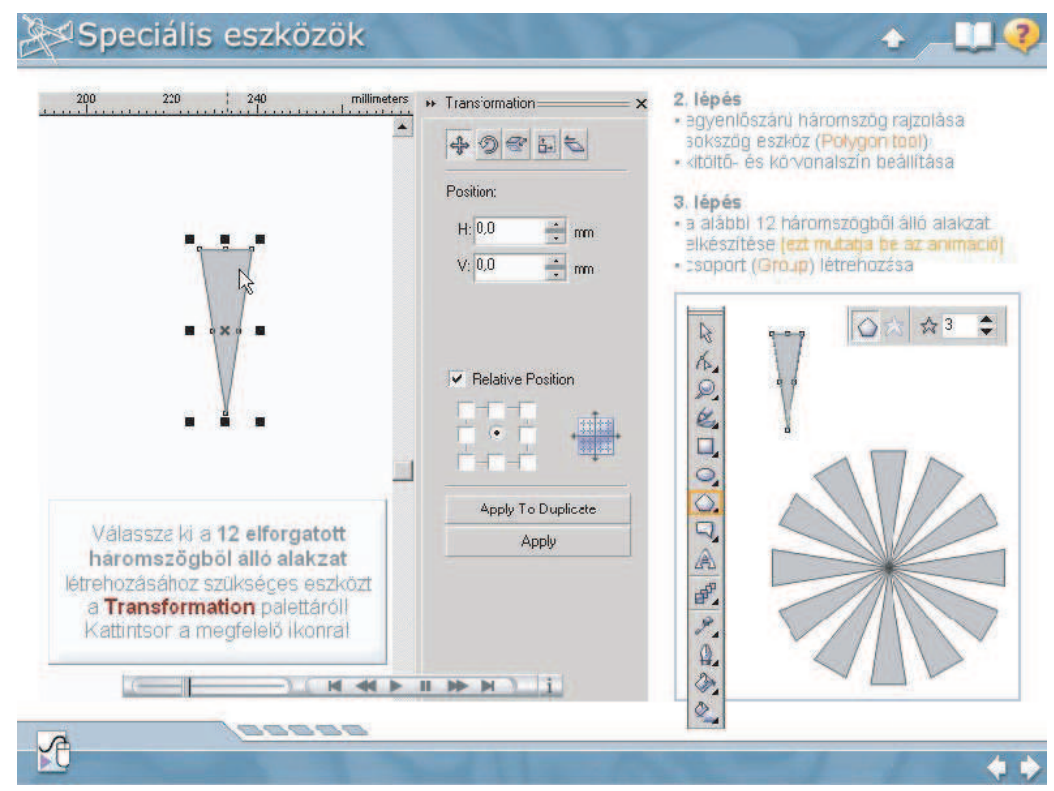

Figure 5. A multimedia based electronic teaching material with different visual-auditory elements (text, image, animation) 
An extensive body of research has established that most people learn most sufficiently with one of the three perceptive modalities (visual, auditory, kinesthetic) and tend to miss or ignore information presented in either of the other two. So there are visual, auditory, and kinesthetic learners. Visual learners remember best what they see: pictures, images, diagrams, flow charts, animations, videos. If something is simply said to them they will probably forget it. Auditory learners remember much of what they hear and more of what they hear and then say. They get a lot out of discussion, prefer verbal explanation to visual demonstration, and learn effectively by explaining things to others. (Waldheim, G. P., 1987)

Most learners are visual while most teaching is verbal, namely the information presented is predominantly auditory (lecturing) or a visual presentation of auditory information (words, symbols written in texts and handouts, on transparencies, on a chalkboard, or on a screen). In an electronic teaching-learning environment it would be very important that a learner could select the appropriate modality forms for him. Therefore the electronic teaching materials could contend encoded information in different forms by which the learner can choose the adequate modality forms (Figure 5).

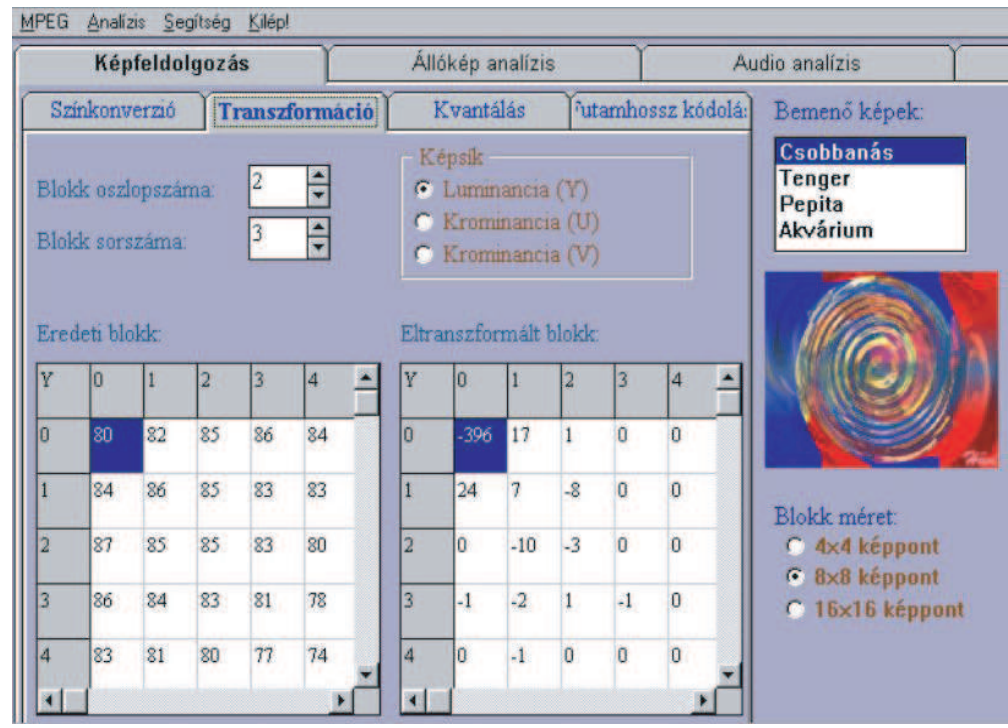

Figure 6. A multimedia based electronic teaching material with interactive contents 


$$
\text { "tothpeter" — 2005/2/17 — 18:12 — page 395 — \#11 }
$$

As seen in Figure 6 the learner can become an active person in teachinglearning process by interactive contents. E.g. the learner can give any input parameter of the process and after that he can analyse the output by which he is capable to draw the conclusion from results. That is an inductive component of the teaching-learning styles (methods).

It is important to mention there are many tests to measure the learner's dominant modality or modalities. E.g., Middlesex Community-Technical College's Modality Preference Inventory contends $3 * 10$ statements (visual, auditory, kinesthetic/tactile modality) and the learner have to select the appropriate number (1-seldom/never, 2-sometimes, 3-often) response as it applies to him. A score of 21 points or more in a modality indicates the strength of that area. The highest of the three scores indicates the most efficient method of information intake. The second one indicates the modality, which boosts the primary strength.

\section{Summary}

It is to be stated that e-learning is an informatically supported, open, electronic, distant form of education where the common means of communication for the organiser of studies, the teacher and the student alike, is the computer or the computer network. By analysing electronic syllabuses we can find the relations between syllabus contents and students' achievement. In the developing process of electronic syllabuses the learning style of participants at the training has to be taken into consideration, too, because given this knowledge the independent learning problems of students can be overcome.

\section{References}

[1] B. S. Bloom, Taxonomy of Educational Objectives: Cognitive Domain, McKay, New York, 1956

[2] M. Conner and W. W. Hodgings, Learning Styles, 2000, http://www. learnativity.com/learningstyles.html.

[3] R. H. Dave, Taxonomy of Educational Objectives and Achievement Testing, In: Developments in Educational Testing, University of London Press, London, 1969.

[4] R. M. Felder and L. K. Silverman, Learning and Teaching Styles in Engineering Education, Engineering Education 78, no. 7 (1988).

[5] C. G. Jung, Harcourt, Brace, New York, 1933. 


$$
\text { "tothpeter" — 2005/2/17 — 18:12 — page 396 — \#12 }
$$

[6] D. A. Kolb, Experience as the Source of Learning and Development, Englewood Cliffs, N. J.: Prentice-Hall, 1984.

[7] D. R. Krathwohl, B. S. Bloom and B. B. Masia, Taxonomy of Educational Objectives: Affective Domain, McKay, New York.

[8] Learning Styles Modality Preference Inventory, Middlesex Community-Technical College, 1964, http://www.commnet.edu/mxctc/clc/survey.htm.

[9] M. D. Merill, Principles of Instructional Design, Englewood Cliffs, New Jersey, 1994.

[10] P. Pentelenyi and P. Toth, ICT Based Technical Teacher Training, In: Proceedings of the 3rd International Conference on Information Technology Based Education and Training in Budapest, Hungary 2002.

[11] C. C. Schroeder, New Students - New Learning Styles, http://www.virtualschool.edu/mon.

[12] Self-scoring Inventory and Interpretation Booklet, McBer \& Company Training Resources Group, Boston, Massachusetts, 1997.

[13] D. Smith and D. A. Kolb, User Guide for the Learning-Style Inventory, Boston: McBer and Company, 1985.

[14] P. G. Waldheim, Understanding How Students Understand, Engineering Education 77, no. 5 (1987).

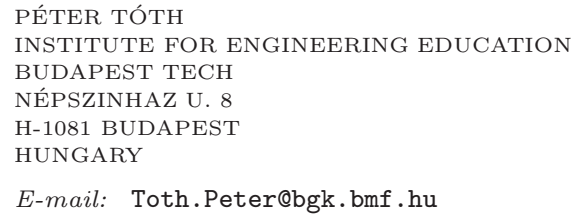

(Received June, 2004) 